\title{
NEURO-FUZZY CONTROLLER FOR ENHANCING THE PERFORMANCE OF EXTINCTION ANGLE CONTROL OF INVERTERS IN A MTDC-AC SYSTEM
}

Jayakrishna. R.

H.S. Chandrasekharaiah

K.G. Narendra

Department of High Voltage Engineering, Indian Institute of Science,

Bangalore, India.

\begin{abstract}
Constant extinction angle control of an inverter in a MTDC-AC system is of utmost importance for proper operation under all contingencies. In this paper, the process of control is treated as a pattern recognition problem. A neuro-fuzzy controller is implemented and used for on-line operation of a MTDC-AC system to enhance the performance of extinction angle control. The proposed controller has significantly improved the system performance for cases studied.
\end{abstract}

KEY WORDS: NEURAL CONTROL, MTDC SYSTEM, DC TRANSMISSION, INVERTER CONTROL

\section{INTRODUCTION}

The control of extinction angle of an inverter in a dc transmission system is of utmost importance [1]. This angle has to be maintained at a value such that the incidence of commutation failure is reduced and the requirement of reactive power compensation is minimised. For this purpose, a number of methods to control the extinction angle have been developed $[2,3]$. With the advent of modern control theory, new techniques like adaptive control, system identification and estimation, etc. have been proposed $[4,5]$, to improve the dc system performance and make it practically free from deleterious effects. As most of these controllers are equipped with limited intelligence and their action is based on the final effects (ex. reduction in extinction angle below the stipulated value) than on the early detection of the primary causes (ex. reduction in 3-phase ac bus voltages, increase in dc current over its rated value, etc.), they are unable to render assistance in proper time. Hence it is necessary to monitor the system to detect faults during their developing stages so that corrective action is taken at an appropriate time to reduce the disturbances.

A typical inverter control scheme operates using the relation, $\epsilon=\left(\delta_{\text {optimum }}-\delta_{\text {actual }}\right)$, where $\delta$ is the extinction angle of the inverter in electrical degrees. This difference termed error in the extinction angle is used to either advance or delay the triggering of the thyristor so that an optimum $\delta$ is maintained by the system.

The motivation to improve the Constant Extinction Angle (CEA) controller is based on the following example.

Consider a decrease in ac bus voltage due to a fault, resulting in reduction of the commutating voltage which feeds the inverter. This causes decrease in dc voltage output of the inverter thereby increasing the dc current. The increase in dc current coupled with decrease in commutating voltage causes overlap angle to increase resulting in decrease of extinction angle, finally leading to commutation failure. Hence there is a need to act on the early detection of primary causes than relying solely on final effects.

In the proposed system, the development of fault is monitored continuously and the corrective action is obtained at an early time so as to limit the 
effects of the disturbance. In general, the commutation process is sensitive to the changes in the ac bus voltages and the dc current. Thus 3-phase ac bus voltages, dc current and the extinction angle have been used to arrive at the state of the system at regular intervals of time. The input data are pre-processed using fuzzy logic and fed to an Artificial Neural Network (ANN) so that the system state is identified and a proper value of the triggering instant is determined which results in a trouble free operation. Thus the structure of the conventional controller is changed so that (a) a number of inter-related factors are considered for arriving at the error criterion for inverter control, and (b) certain amount of intelligence is imparted to the controller so as to equip it with self-learning ability. This system is termed as the Multi-Input-SingleOutput (MISO) controller. The following sections discuss the implementation details of such a controller so that on-line operation is possible. The performance of proposed controller is presented for a case study involving fault on the ac system fed from inverter.

\section{IMPLEMENTATION OF NEURO-FUZZY CON- TROLLER}

\subsection{System Considered}

The system considered is a 4 terminal, mesh connected MTDC-AC system shown in fig. 1.0. The dynamic, digital simulation of the above system is carried out using a software package developed in [6]. The details of the system data are available in appendix $A$. The controller discussed above has been implemented and embedded into the dc system for on-line studies. The implementation details are described below.

\subsection{Pattern Vector Generation Using Fuzzy Logic}

The 3-phase ac bus voltages, dc current and the extinction angle of inverter 2 constitute input to the CEA control system. The deviation of these variables from their respective steady state values are used to classify the variation in system status. This classification being imprecise, fuzzy logic is used to arrive at meaningful results. Typically these classes can be treated as linguistic variables, similar to the way human beings would classify. An example of this classification is given below.

The difference in the measured and the reference dc current waveforms are classified as follows.

Let this difference be $X$.

$$
\begin{aligned}
& \text { IF } \quad(-0.05 \geqslant X \leqslant 0.05) \quad \text { THEN NORMAL } \\
& (0.05>X \leqslant 0.1) \quad->\quad \text { SLIGHTLY HIGH } \\
& (0.1>\mathrm{X} \leqslant 0.2) \quad-->\quad \text { VERY HIGH } \\
& (\mathrm{X}>0.2) \quad-->\quad \text { VERY VERY HIGH } \\
& (-0.1 \geqslant X<-0.05) \quad-->\quad \text { SLIGHTLY LOW } \\
& (-0.2>X<-0.1) \quad-->\quad \text { VERY LOW } \\
& (\mathrm{X}<-0.2) \quad->\quad \text { VERY VERY LOW }
\end{aligned}
$$

Suitable membership values are assigned for these classes so that class boundaries are flexible. A membership value of $[0.0,0.5,1.0,0.5,0.0]$ is used here. For example, if $X=0.0$, then using the above table and the membership function, the pattern vector is determined as a $1 \times 7$ vector. $P V=[0.0,0.0,0.5,1.0,0.5,0.0,0.0]$. In a similar way, pattern vector corresponding to 3-phase ac bus voltages and extinction angle are generated. Altogether, they form a pattern vector of dimension $(1 \times 35)$. This forms the input to the ANN.

\subsection{Adaptive Pattern Recognition Using Artificial Neural Networks}

The problem of control can be defined as determination of the mapping between the observations of the system state and the actions to be carried out. Thus it constitutes a pattern recognition problem [7]. The observations are quantified as a pattern vector representing the status of the system. The actions are quantified as a pattern vector of desired control inputs. There are a number of techniques available to solve this problem. ANNs are a new class of computing paradigm which imitate the behaviour of human being's problem solving capabilities $[7,8,9]$. They can be trained to learn the mapping between the input and output vectors. The major advantages of ANN over conventional pattern recognition approaches are that the former can respond to untrained situations by virtue of its interpolating abilities and offers good noise rejection capability.

There are mainly two kinds of ANNs, 1) Supervised and 2) Unsupervised neural networks. We have employed the supervised ANN called the FeedForward, Multi- layered Perceptron with Back Propagation learning algorithm $[10,11]$. Brief particulars of architecture of ANN used are shown in fig. 2.0 .

The system state pattern vector forms the in- 
put to the ANN. It maps this input vector onto the output vector using a non-linear transfer function usually a sigmoid. The output pattern vector corresponds to the magnitude of desired triggering angle of the inverter which ensures safety as per the domain expert's opinion. Hence it is termed as supervised control. In order to train the ANN, a number of training pattern pairs are required. Out of about 16,000 possible pattern pairs, 124 pattern pairs were synthetically created and used as the training set. The samples were carefully drawn to encompass all possible system states. Training was stopped once the difference of the network's response to input patterns was within $\pm 2 \%$ of the desired response. The total time required for learning all the pattern pairs was about 6 hours on a PC-AT 386 running Q $25 \mathrm{MHz}$. After the ANN is trained, it is tested using pattern pairs generated by the actual system. It performed satisfactorily when exposed to the testing set. The tested neural network was then embedded into the dc system so that the neural controller became operational on-line in order to improve the dynamics of the system during disturbances achieving faster recovery from faults. Although, the neural controller is active continuously, thyristors can be triggered only at discrete intervals of time. The output suggested by the neural controller is in relation to the present system status. In order to utilise the past data and to incorporate the constraints on the extinction angle, the triggering angle suggested by the neural controller is processed through a decision maker, which is a collection of number of rules implemented using IF-THEN-ELSE statements.

\section{RESULTS AND DISCUS- SION}

\subsection{Case Study 1: Conventional CEA Controller at In- verter 2}

Initially the MTDC-AC system is simulated for steady operating conditions. The system performance under this condition is satisfactory.

Solid single line to ground fault at INV 2 ac bus :

Any fault on the ac system connecting an inverter generally leads to commutation failure of that inverter. A solid single-line-to-ground fault on the ac bus 4 was simulated for a duration of $5 \mathrm{~ms}$. Fig. 3.0 indicates the performance of conventiona' controller. Eventhough the $\mathrm{PI}$ controller used has been optimised to give best transient performance, the system undergoes commutation failure as soon as $\delta$ of the inverter bridge decreases to a very low value. The dc currents increase to a very large value of about $4.5 \mathrm{pu}$. The system gradually approaches steady conditions after about 15 cycles. The conventional controller acts mainly on the final effects of the fault i.e., decrease in extinction angle below its optimum value. By the time the conventional controller gives the correction it is too late to prevent the occurrence of commutation failure. It can also be seen that, both the rectifiers and inverter 1 have also been affected due to the fault.

\subsection{Case Study 2: \\ Neuro-Fuzzy CEA controller at In- verter 2}

The performance of the proposed controller is found to be satisfactory for steady state operations of the MTDC-AC system.

Solid single line to ground fault at INV 2 ac bus :

A solid single line to ground fault was simulated on the ac bus 4 for a duration of $5 \mathrm{~ms}$. Fig. 4.0 presents the performance of the system equipped with the proposed neuro-fuzzy controller. It is able to prevent the system from undergoing commutation failure. The dc current of the faulted inverter is restricted to about $2.0 \mathrm{pu}$. The rectifier currents are almost undisturbed. In about 12 cycles the system is able to settle down to steady operating conditions. The delay in settling times is mainly due to interaction of the controllers of the inverters 1 and 2 . The primary objective of the proposed controller is to reduce the incidences of commutation failures. This has been achieved significantly.

The case studies presented reveal the overall performance of the proposed neuro-fuzzy controller vis-a-vis the conventional controller. The proposed controller is able to prevent the occurrence of commutation failure by dynamically varying the triggering angle of the inverter bridge. Further studies are required to test the proposed controller to critically examine its performance under various system contingencies especially when the inverter is feeding into weak ac system. 


\section{CONCLUSIONS}

The proposed neuro-fuzzy controller has performed satisfactorily for the case studied. This can be attributed mainly to the look ahead nature of the controller coupled with the integration of multiple sensors. It is possible to implement this controller to perform on-line for real time applications. A transputer based multi-processing architecture is being developed for real time simulation studies.

\section{ACKNOWLEDGEMENTS}

The authors acknowledge Prof. G. R. Nagabhushana, Chairman, Department of High Voltage Engg., I.I.Sc, for his interest in this work.

\section{APPENDIX A}

The system considered is a 4 terminal, mesh connected, hypothetical dc transmission system. The details of this system are

AC SYSTEM:

Rated Voltage : $345 \mathrm{kV}$ at the ac bus Short Circuit Ratio : 20.0 at all stations

DC SYSTEM:

Rated Voltage: $500 \mathrm{kV}$ at each converter station dc bus

Rated Power : $500 \mathrm{MW}$ at each converter station DC LINE:

Line 1: $400 \mathrm{~km}$, Line $2=600 \mathrm{~km}$, Line $3=600$ $\mathrm{km}$, Line $4=800 \mathrm{~km}$.

Surge impedance of each line $=334 \Omega$.

TERMINAL COMPONENTS AT EACH AC BUS

The following filters are connected: 5 th, $7 \mathrm{th}, 11 \mathrm{th}$, 13th and High Pass.

Reactive Power Compensating capacitor $=0.04$ $\mu \mathrm{F}$.

Local Static Load : $100 \Omega, 1 \mathrm{H}$.

CONTROLLERS:

The MTDC-AC system is equipped with Current Margin Control for current order co-ordination. At each of the rectifier station, a PI current controller is present. At inverter 1, conventional Minimum Extinction Angle control (MEA) is employed along with Inverter One Way Current Control. The proposed neuro-fuzzy controller replaces the conventional control for studies.

\section{REFERENCES:}

1 E. Uhlmann, " Power Transmission by Direct Current", Springer Verlag, Berlin/Heidelberg, 1975.

2 J. Arrillaga and G. Galanos," Theoretical Basis for a Digital Method of Grid Control for HVDC Converters ", IEEE trans. on PAS, Vol. 89, No. 8, Nov/Dec. 1970, pp. 20492055.

3 R. Joetten, J.P. Bowles, G. Liss, C.J.B Martin and E. Rumpf, "Control in HVDC systems", The state of the art, part II: "Multi- terminal systems', CIGRE, paper 14-07, 1980.

4 S. Lefebvre, M. Saad and R. Hurteau," Adaptive Control for HVDC Power Transmission System", IEEE Trans, PAS, Vol 104, 1985, pp 2329- 35.

5 S. Bhattacharya and H.W Dommel, "A New Commutation Margin Control Representation for Digital Simulation of HVDC System Transients", IEEE Trans. on Power Systems, Vol. 3, No. 3, Aug., 1988, pp. 1127-1132.

6 Premila Manohar, "Digital Simulation Study of the Application of Artificial Commutation in MTDC Systems Including Weak ac Systems", Ph.D Thesis, I.I.Sc , 1990.

7 P. Werbos, "Backpropagation and Neurocontrol: A Review and Prospectus", Proc. Int. Joint Conf. Neural Networks (IJCNN), New York, IEEE, June 1989, pp |-209 to I-216.

8 Yoh-Han Pao, "Adaptive Pattern Recognition and Neural Networks", AddissonWesley, 1990

9 T.S. Dillon," Artificial Neural Network Applications to Power Systems and Their Relationship to Symbolic Methods", Electrical Energy and Power Systems, 1991, pp. 66-72.

10 Rummelhart, Hinton and Williams, "Learning Internal Representations by Error Propagation", Parallel Distributed Processing, Cambridge, Mass.: MIT Press, 1986, Vol. 1.

11 R. Hecht-Nielsen," Theory of the Backpropagation Neural Network", Proc. Intl. Joint Conf. Neural Networks (IJCNN), Vol. 1, pp 593-605, 1989. 


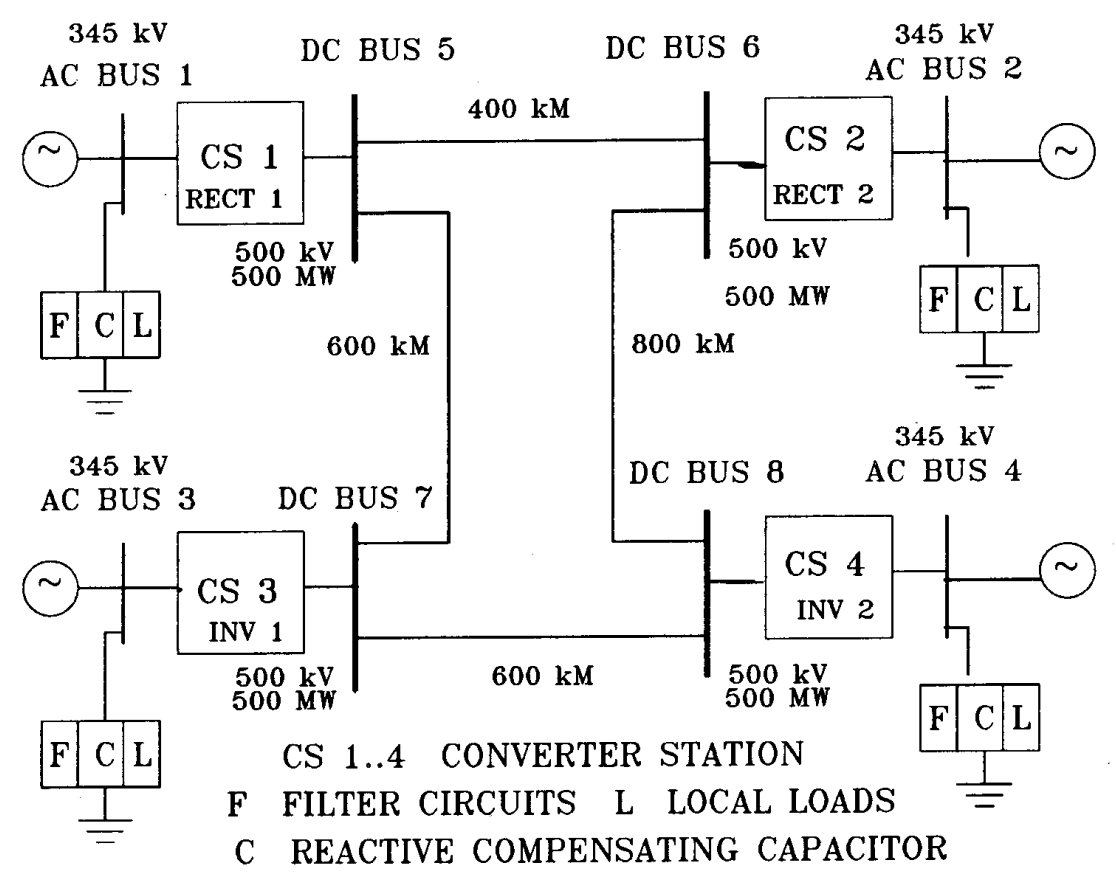

FIG. 1.0 SCHEMATIC OF THE MTDC-AC SYSTEM

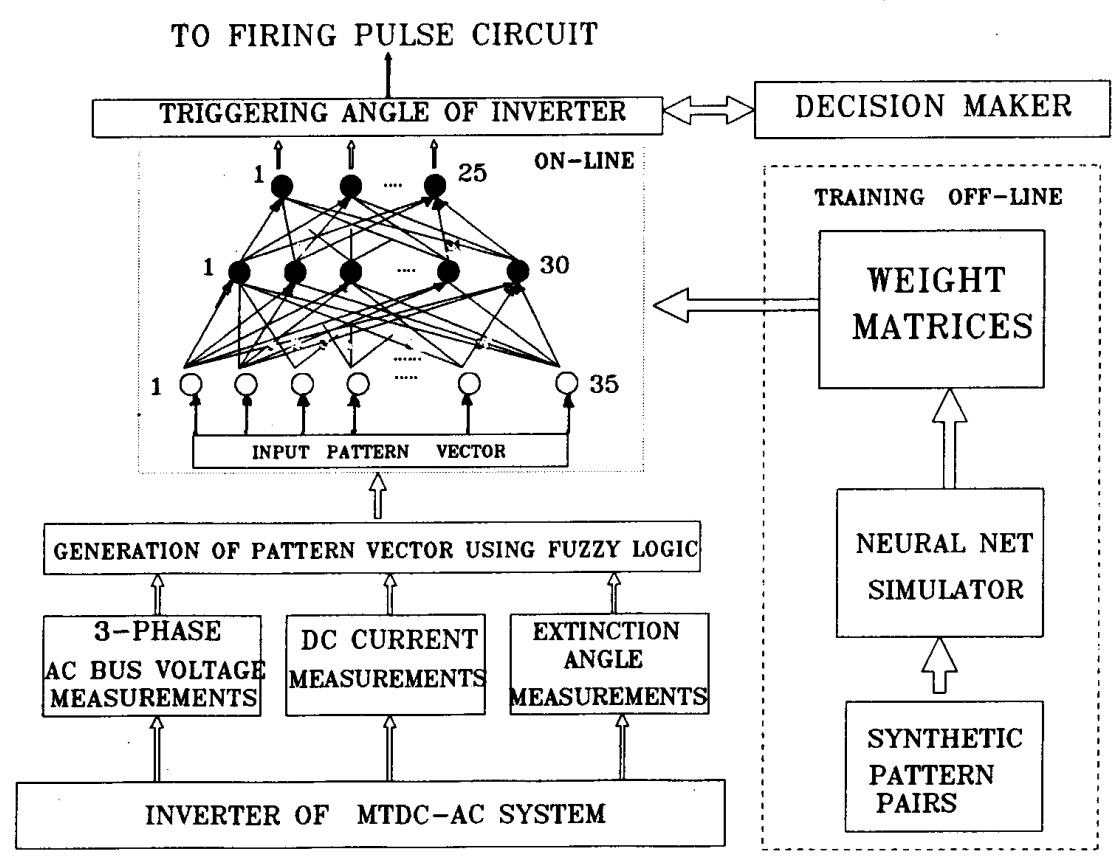

FIG. 2.O ARCHITECTURE OF NEURO-FUZZY CONTROLLER USED 


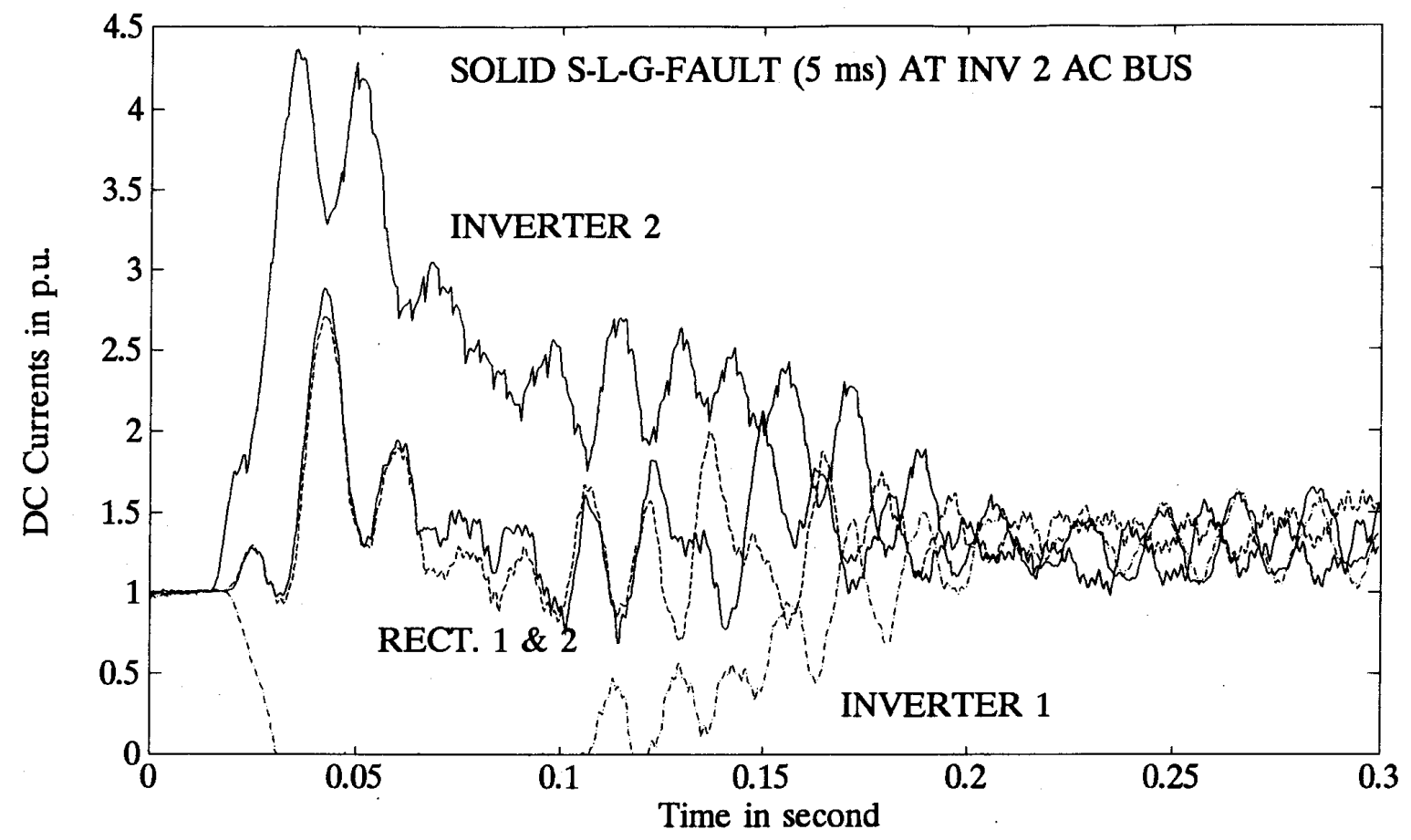

FIG. 3.0 PERFORMANCE OF CONVENTIONAL CONTROLLER

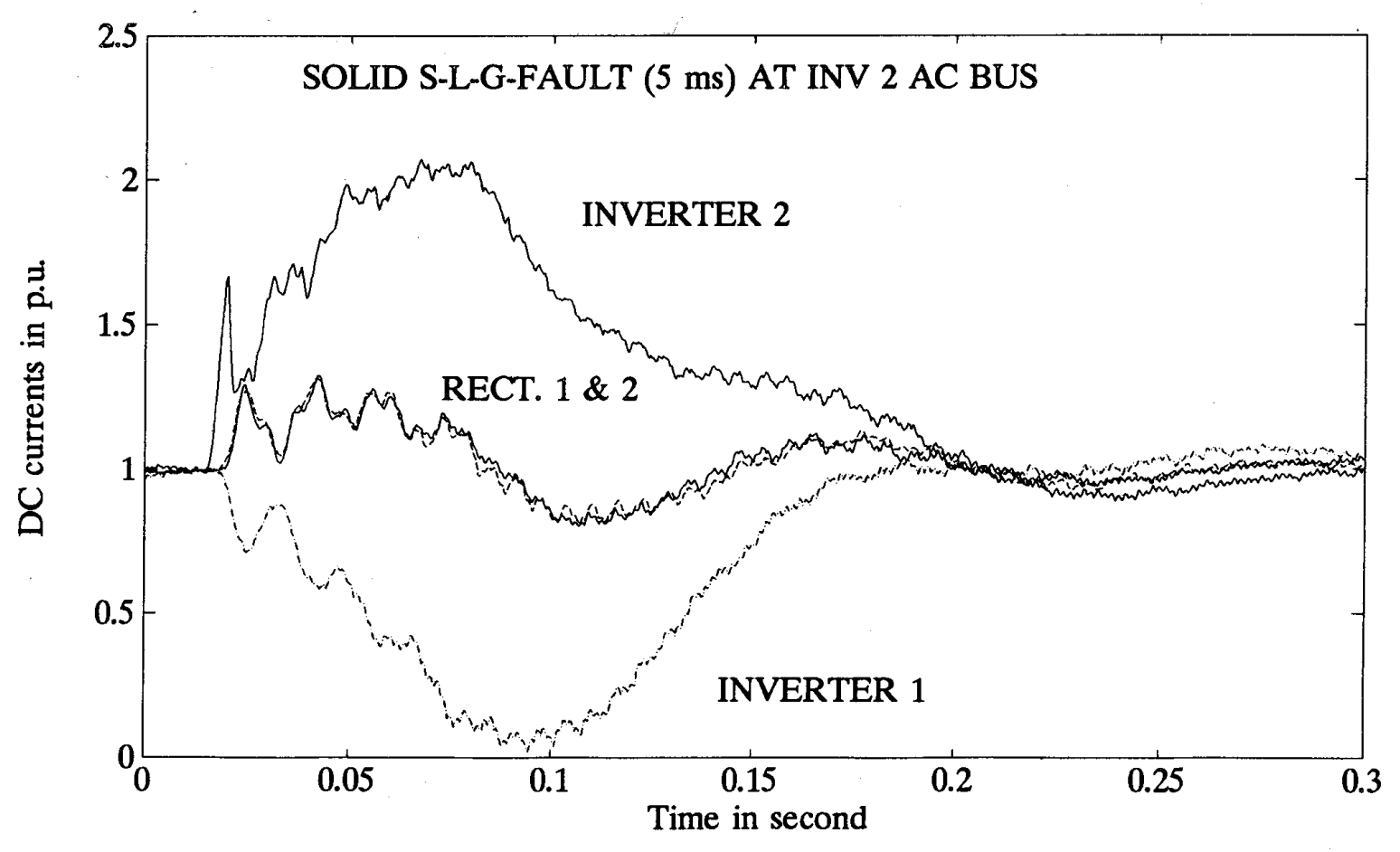

FIG. 4.0 PERFORMANCE OF NEURO-FUZZY CONTROLLER 